ON THE RECORD

“Had the decision

been mine, we would

not have built the space

station we're building

in the orbit we're

building it in."

NASA administrator Michael Griffin attacks the International Space Station.

\section{“Having a moon is} just inherently cool and it is something that most self-respecting planets have."

Astronomer Michael Brown talks about thediscovery of amoon orbiting the Solar System's 'tenth planet'.

Source USA Today, Caltech

\section{SCORECARD}

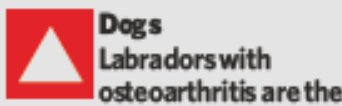

focus of a study launched at the University of Liverpool, UK. Researchers will use magnetic resonance imaging to track disease progression in the dogs.

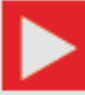

Nuclear safety Ukrainian officials have recovered14 pieces of nuclear fuel stolen from the nowdefunct Chernobyl power plant. The rods, found in a plastic bag near the plant's perimeter, had been missing for a decade.

$\checkmark$ Archaeology Embarrassed Czech archaeologists have found that a statuette thought to represent a fifth-century Persian goddess came from a mould made in 1968 by a local pensioner.

\section{NUMBER CRUNCH}

\section{$60 \%$ of PhD-granting physics} departments in the UnitedStates report visa problems for foreign students retuming after trips abroad.

$48 \%$ of the physics departments had at least one foreign student who was denied entryor considerably delayed by visa problems.

$13 \%$ is the fall in the number of first-year enrolments by foreign graduate students in the United States between 2000 and 2004.

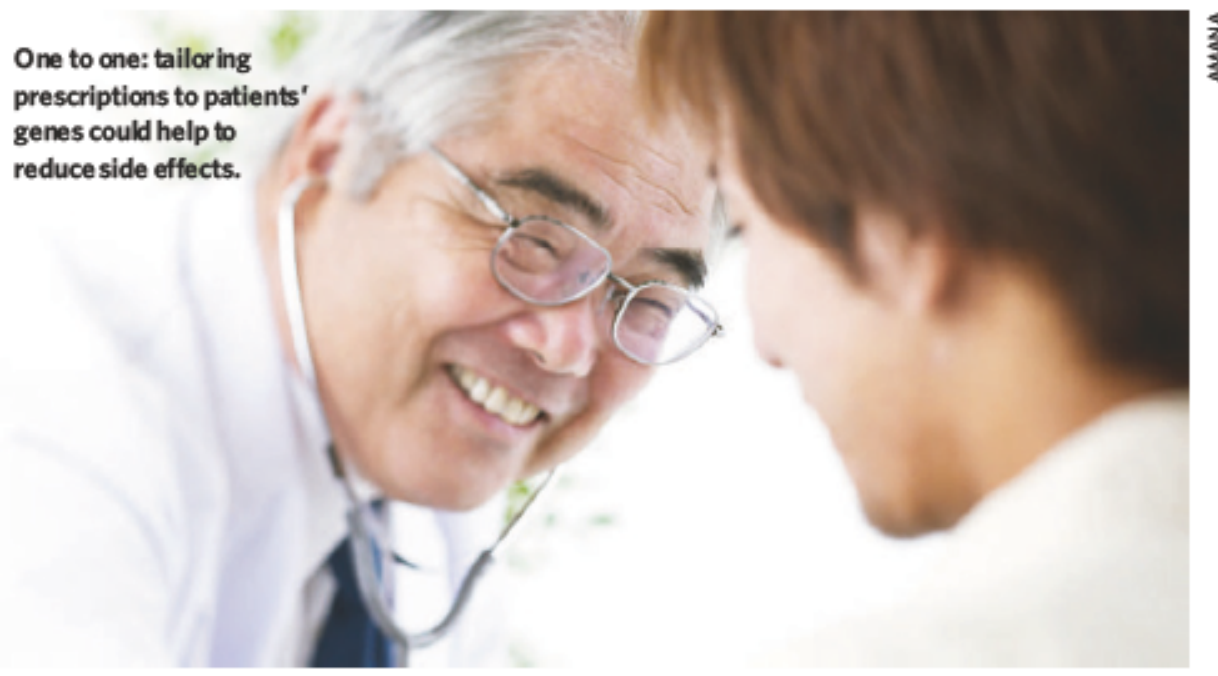

\title{
Japan jumps towards personalized medicine
}

\section{TOKYO}

Japanese companies say they have built a desktop machine that will allow doctors to assess patients' DNA from a single drop of blood, and so tailor treatment to an individual's genes. The machine can deliver results within an hour, they say, and will be on sale for 5 million yen (US\$44,000) by autumn 2006.

Safe dosage, effectiveness and side effects for any given drug vary from patient to patient. And determining which drug and dosage is best for any given individual is a critical challenge facing healthcare specialists.

But the announcement about the Japanese machine on 27 September came just a week after scientists in the United Kingdom spoke out against the hype surrounding personalized medicine. A report produced by the Royal Society warned that prescriptions tailored to a patient's genes are at least 15 to 20 years away.

The Japanese device was developed by the genomics facility of the Institute of Chemical and Physical Research (RIKEN) in Yokohama, the printing company Toppan in Tokyo, and the Kyoto-based maker of scientific equipment Shimadzu. Shimadzu's Takaaki Sato, who led Shimadzu's development efforts, says the key advance is a chip that analyses DNA in a blood sample, thereby bypassing the timeconsuming DNA purification steps currently needed.

Although Sato will not give further details, he says that any health worker could use the machine to test a drop of blood for a particular genotype, and get a result in an hour. ${ }^{\alpha}$ Patients do not want to wait a week or even a day for results before being able to take a medicine, especially if they have an infectious disease," says Sato.

According to RIKEN and Shimadzu, the machine will first be tested on patients being prescribed one of two medicines: an antibody called irinotecan, which can cause hearing loss in people with a certain mutation in their mitochondrial DNA, and the anticoagulant warfarin, which causes excessive bleeding in some patients.

But there is scepticism over how useful the device will be. David Weatherall of the Weatherall Institute of Molecular Medicine at the University of Oxford, UK, who worked on the Royal Society report, says the metabolism of warfarin is related to at least two genes whose interaction is not understood. Other factors, such as the patient's age or additional drugs being taken, also need to be considered, he says.

"There is no way around these problems except to test each drug independently in large population studies, and to monitor all these issues over several years," he says. "There is still a huge gap between the scientists who do this kind of work and its application for practical purposes."

Sato admits that initially his machine will be most useful for research. But judging from the "unbelievable number of responses" received since announcing the test, he says there is no way that 15 years will pass before doctors are using such devices for day-to-day diagnosis and treatment.

David Cyranoski 